\section{Image Compression by Wavelet Packets}

\section{NORA OMRAN ALKAAM*}

Al mustansiriya university, College of science, Iraq.

\section{Abstract}

This research implementslmage processingto reduce the size of image without losing the important information. This paper aims to determine the best wavelet to compress the still image at a particular decomposition level using wavelet packet transforms.

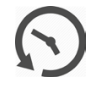

Article History

Received: 10 February 2018

Accepted:19 March 2018

\section{Keywords}

Image compression, Wavelet packets.

\section{Introduction}

Image compression is a data compression application that encodes the original image with a few bits. The aim of image compression is to reduce the frequency of image and store or transfer data in an effective format.It also reduces the time required for images to be processed in the specificsystem.

\section{Wavelet Packets}

The wavelet packets is the generalized approach of wavelet decomposition which introduces a spacious area of the possibility of signal analysis that is permits the better accordance analysis to the signal. It transforms the signal to the frequency domain level. The WP divides the low and high frequency subband. In the wavelet analyzing, the signal is divided into an1approximation and a detail ${ }^{1}$ coefficient. Then an approximation is also divided into a next level approximation and detail, And continue this technique until they reach a particular level ${ }^{1}$, but in wavelet packet analysis , this process also achieved on the details. WP is a part of the wavelet transform (WT ), the lowpass filter and the highpass filter output repeated to offer a more flexible and complex analysis. In composition process, n-level may give $\mathrm{n}+1$ methods for signal decomposition. figure $(1)^{2}$.

To compute WP Webegin with two filters of length $2 \mathrm{~N}$.

$$
\begin{aligned}
& \text { Wn }(x), \quad n=(0,1,2,3) \\
& W 2 n(x)=\sqrt{2} \sum_{k=0}^{2 N-1} h(k) \quad W n(2-k) \\
& W 2 n+1(x)=\sqrt{2} \sum_{k=0}^{2 N-1} g(k) W n(2 x-k)
\end{aligned}
$$

\footnotetext{
CONTACT Nora Omran nora.omran@yahoo.com 9 Al mustansiriya university, College of science, Iraq.

() 2018 The Author(s). Published by Oriental Scientific Publishing Company

This is an 6 Open Access article licensed under a Creative Commons Attribution-NonCommercial-ShareAlike 4.0 International License (https://creativecommons.org/licenses/by-nc-sa/4.0/ ), which permits unrestricted NonCommercial use, distribution, and reproduction in any medium, provided the original work is properly cited.

To link to this article: http://dx.doi.org/10.13005/ojcst11.01.05
} 
$h(n)$ and $g(n)$, identical to the wavelet. $W_{0}(x)=\Phi(x)$ is the scaling function and $W_{1}(x)=\Psi(x)$ is the wavelet function ${ }^{3}$.

Wavelet packets has the ability to further degrade the area of wavelets as follows:

$\mathrm{V}_{0}=\mathrm{V}_{1} \oplus \mathrm{W}^{1}=\mathrm{U}^{0} 1 \oplus \mathrm{U}^{1} 1=\mathrm{U}^{0} 2 \oplus \mathrm{U}^{1} 2 \oplus \mathrm{U}^{2} 2 \oplus \mathrm{U}^{3} 2$

$=\ldots=U^{0} N \oplus U^{1} N \oplus \ldots \oplus U^{2} N^{N-1}$ where $\mathrm{V}_{0}$ is the signal space $\mathrm{V} 1$ and $\mathrm{W} 1$ are the approximation and detail of $\mathrm{V}_{0}$ respectively; $\mathrm{U}^{0} \mathrm{~N}, \mathrm{U}^{1} \mathrm{~N}, \ldots, \mathrm{UN}^{2 \mathrm{~N}-1}$ are the subspacesof $\mathrm{V}_{0}$;

$\mathrm{N}$ is decomposition series. The wavelet packet decomposition tree for $\mathrm{N}=2$ is shown in Figure $(2)^{4}$.

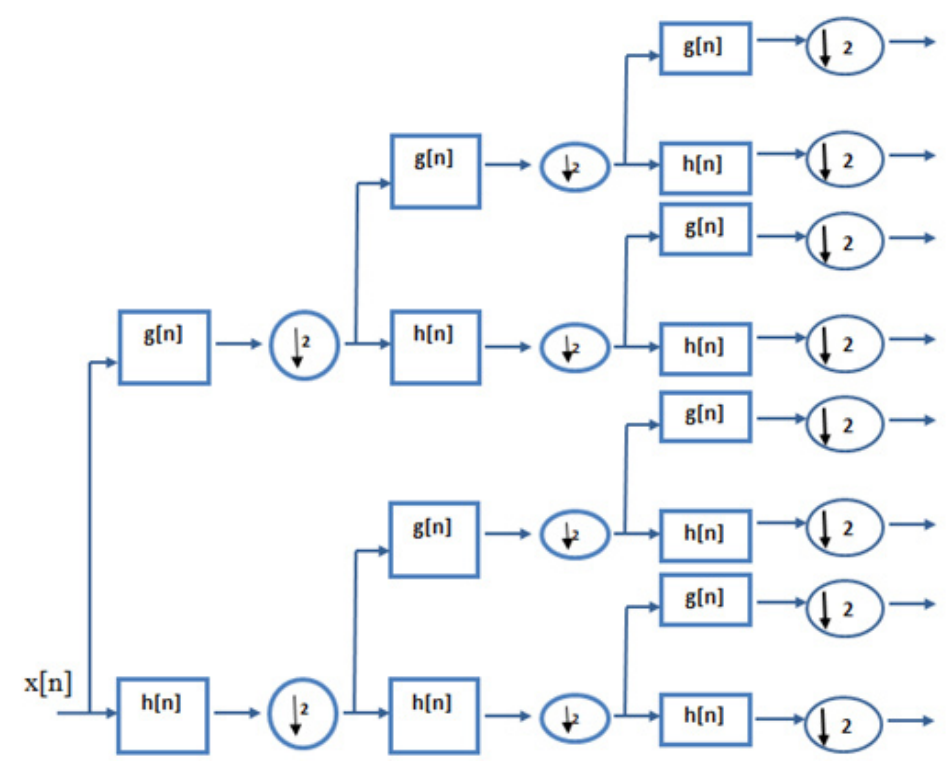

Fig. 1: Wavelet packets decomposition

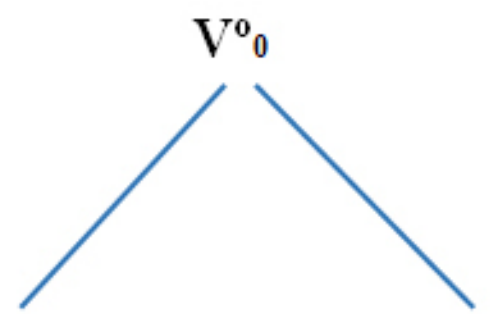

$\mathrm{U}^{0}{ }_{1} \mathrm{U}^{1}{ }_{1}$

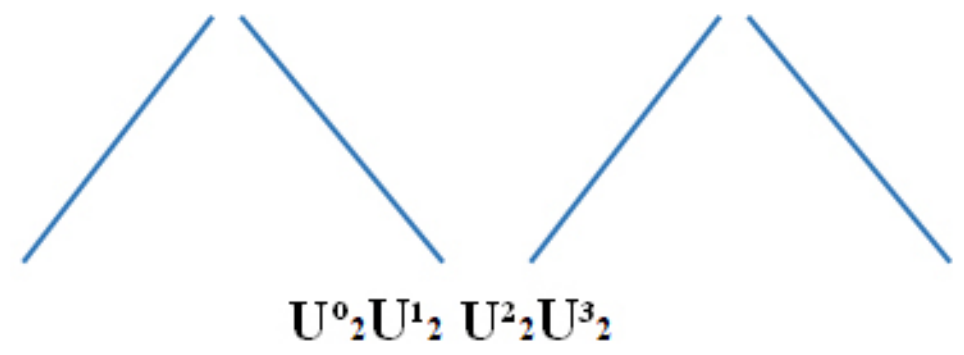

Fig. 1: Wavelet packets decomposition tree 
A single wavelet packets tree precedent numerous decomposition options wavelet packet decomposition of a signal, results in a considerable redundancy and an increase in the number of wavelet bases in which the size of the library will grow rapidly when the number of scale levels is increased. Redundancy results in a substantial increase of both computational and storage costs.

A pruning algorithm is needed for selecting a subset of nodes for signal representation considered suitable for a given application and reducing computational costs. These nodes should provide a sufficiently accurate approximation to a given signal.The Shannon entropy function Measuring signal economy.

$\operatorname{cost}_{\text {shammon }}=-\sum_{n} s[n]^{2} \log \left(s[n]^{2}\right)$

An efficient algorithm for finding minimal entropy solutions in easily constracted :

For each node of the analysis tree, beginning with the root and proceeding level by level to the leaves:

- Compute both the entropy of the node, denoted Ep(for parent entropy) \& entropy of its four offspring _denoted EA..EH.. EV.. and ED for two dimensional wavelet packets decomposition: the parent is a two dimensional array of approximation or detail coefficients ; the offspring are the filtered approximation: horizontal;vertical and diagonal details.

- If the mereged entropy of spring is less than the entropy of the parent that is :EA + EH + $E V+E D 1<E p$ include the offspring in the analysis tree If the combined entropy of the offspring is greater than or equal to that of pruning the father-offspring keeping only the parent is the leaf of the optimal analysis tree. (we can write the step 2 in another form for clarity) ${ }^{5}$.

If there is a noleaf node; $\mathrm{C} 1$ is the cost value for the node, The value $\mathrm{C} 2$ is the sum of the costs values of children of that node:

- If $(\mathrm{C} 1<=\mathrm{C} 2)$ then we mark the node as part of the best basis group and cancel any marks in the nodes in the subtree of the current node.

- If $(\mathrm{C} 1>\mathrm{C} 2)$ then the cost value of the node is replacing with $\mathrm{C}^{6}$.

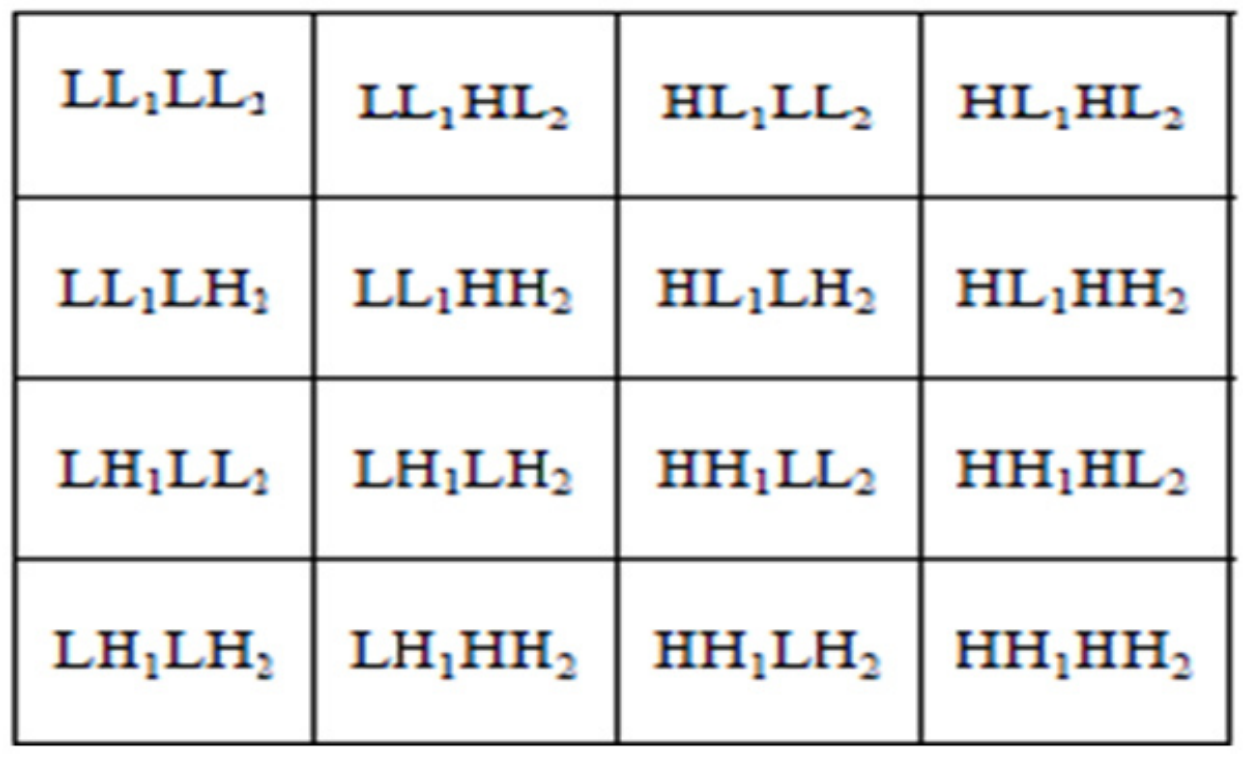

The structure of two level decomposition of wavelet packets 
The Steps of Image Compression

Step 1: Input the Image

In this step the given fingerprint/ iris image size will be checked. Since the system here implemented

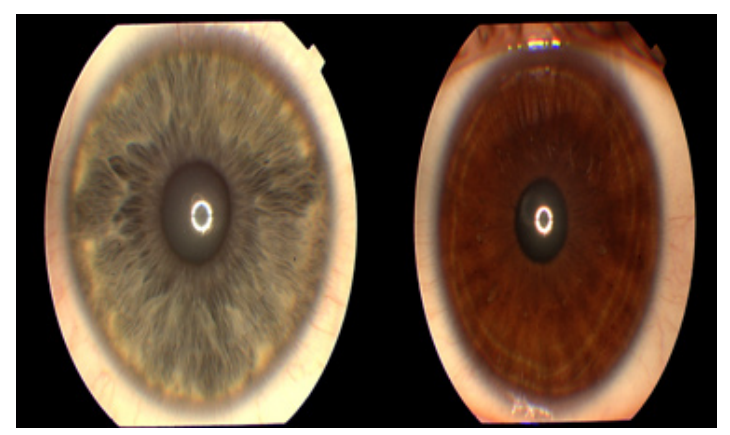

on the image of size 256 * 256 and (.tif , .png) type. This size is common and has been used by many standard systems in the world. in figure (3) below some of fingerprint and iris samples.

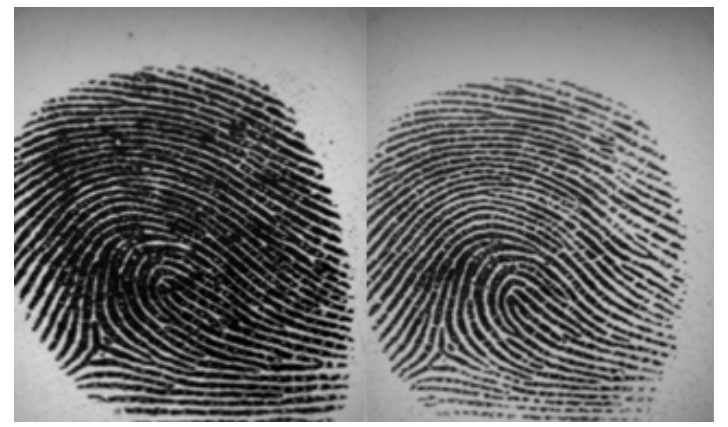

Fig. 3: Samples of fingerprint and iris

Step 2: Applied wavelet packets transform on images

In this step the wavelet packets transforms applied on images that which be $\left(256^{\star} 256\right)$ dimensions to get the required dimension of each image, here We adopted $128^{*} 128$ as a standard dimensions that results from one level of wavelet packets without losing the important information as in figures $(4,5)$. The details of wavelet packet transform that applied in this paper listed in the algorithm below:

\section{Wavelet Packets Algorithm}

\section{Step 1}

Read the image (covert it to a matrix) and do the next steps.

\section{Step 2}

Select a wavelet function (W) "like Daubechies or Haar.".

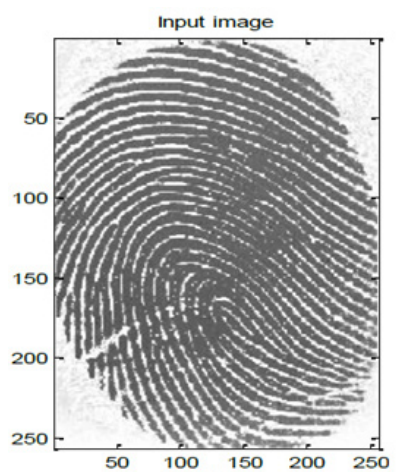

(a)

\section{Step 3}

Specify the decomposition level. "1,2,3..."

\section{Step 4}

Applied WPT and return reduced image (matrix) size .

\section{Step 5}

Save the result of step 4 in a new matrix.

\section{Step 6}

Repeat steps 2...5 for all images.

\section{The Results}



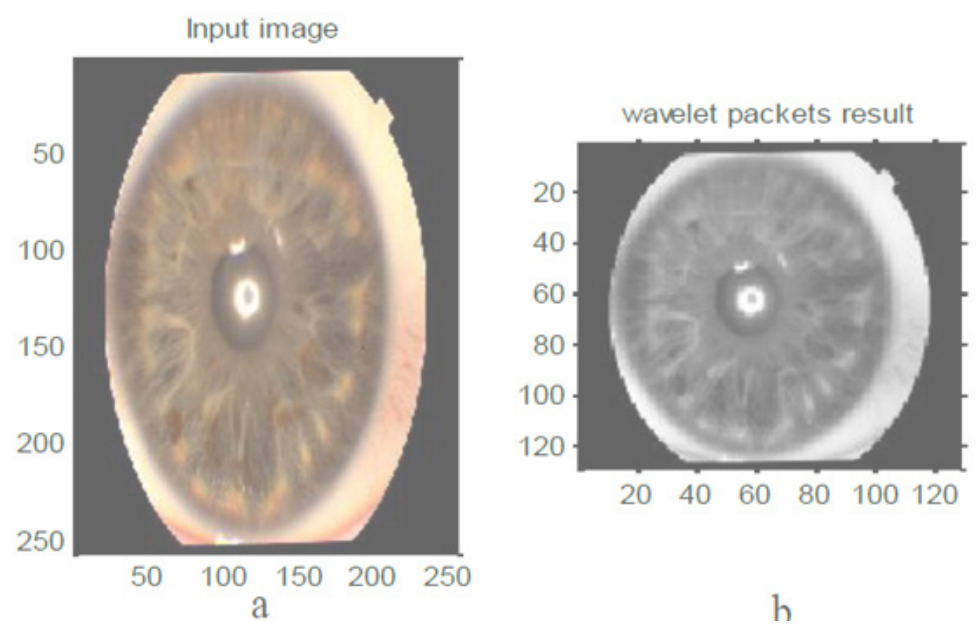

Fig. 5: Wavelet packets for iris image

\section{The Database}

The samples of the fingerprint images are taken from the CASIA database website and iris images taken from the Palacký University iris database fingerprint samples are gray scale of .tif image file format, and the iris samples are .png image file formats.

\section{Reference}

1 M. Y. Gokhale, DaljeetKaurKhanduja, Time Domain Signal Analysis Using Wavelet Packet Decomposition Approach, Int. J. Communications, Network and System Sciences, 2010.

2 Vimal Krishnan V.R, BabuAntoP, Features of Wavelet Packet Decomposition and Discrete Wavelet Transform for Malayalam Speech Recognition, International Journal of Recent Trends in Engineering, Vol. 1, No. 2, May 2009.

3 Jagannath Sethi, Sibaram Mishra Prajna Parimita Dash, Sudhansu Kumar Mishra,
Sukadev Meher, Image Compression Using Wavelet Packet Tree, ACEEE Int. J. on Signal \& Image Processing, 2011.

X. Zhang,Z. Wang, and D. Xu, wavelet packet transform based least mean square beamformer with low complexity ,Progress In Electromagnetics Research, PIER 86, 291-304, 2008.

5 Rafael C. Gonzalez,Richard E. Woods, Digital Image Processing ,2011.

6 K.P.Soman, K.I. Ramachandran, N.G.Resmi ,Insight Into Wavelets : from Theory to Practice, $3^{\text {rd }}$ edition , 2010. 